\title{
Networking
}

\section{Developing primary care research: primary care trusts - a natural home?}

David Kernick St Thomas Health Centre, Exeter, Jonathan Stead Wyndham House Surgery, Silverton and Yvonne Carter Department of General Practice and Primary Care, Queen Mary and Westfield College, Medical Sciences, London, UK

The Government's modernization agenda (DOH, 2000a) and the creation of a two-tier research funding system (DOH, 2000b) marks the third phase in the evolution of primary care research offering new possibilities for a genuine realignment of objectives which to date have only been partially realized. How has the research agenda in primary care evolved and in which direction should it be encouraged?

In 1988, the House of Lords Select Committee on Science and Technology (House of Lords, 1988) drew attention to a dissonance between the research requirements of the NHS and the activities of medical researchers. This report led to the creation in 1992 of an NHS Research and Development Directorate and a national strategic framework responsive to the needs of the evolving health service. At this time, the focus in primary care had been to establish an academic credibility for the discipline in its own right rather than influence the research agenda and by 1995 Departments of General Practice had been established in all UK medical schools.

The second phase of primary care resarch was to be influenced by a commitment to primary careled NHS (DOH, 1996) and a broader research agenda (DOH, 1997). The emphasis now was on the development of research expertise in primary care with the objective of creating an evidencebased culture - a confident assertion that the

Address for correspondence: Dr David Kernick, St Thomas Health Centre, Cowick Street, Exeter, Devon, EX4 4HJ, UK rigorous application of science would generate knowledge and the health care system could be engineered to achieve specific goals. This expansion saw the development of research practices and networks, but existing structures within universities and funding organizations remained largely untouched. A new feature was the acceptance of qualitative research complimenting more traditional methodologies and a more active and participatory role of the patient in research at all levels (Blaxter, 1995).

However, by the end of the decade there still remained a mismatch between the research effort and the needs of research consumers (Tallon et al., 2000). In primary care a dissonance between academic theory and the reality of health service delivery precluded a workable strategy to integrate research into practice. General Practitioners still found it difficult to follow evidence-based guidelines (Salisbury et al., 1998) and the perspectives of those delivering the service often contrasted with national research priorities (Whitford et al., 2000). Health managers were fairing little better exposed as 'organisations under seige - barely coping with the lack of skills to fulfil current agenda, apathy amongst the majority and a capacity to present glossy corporate images that belie the problems of working in a complex organization' (Marshall, 1999). Even former directors of NHS Research and Development were unable to agree whether needs-driven research should be independent of clinical service provision (Swailes, 2000) or whether practising clinicians working 
alongside managers should devise, introduce and test new approaches (Peckham, 1999).

The time for a third phase in primary care research seemed overdue, but how should it evolve?

There will still be a need for central evidencebased allocation decisions taken by bodies such as NICE. However, due to the rapid pace of change and importance of local commissioning, research must be redirected to meet the needs of local managers and practitioners with the fundamental objective of facilitating the allocation of limited resources. Primary care research then becomes an integral part of the health delivery system recognizing the importance of inter-professional working, universality of ownership and the integration of clinical governance, clinical practice and professional development.

Research methodology also needs to evolve to reflect the fact that health systems are complex and difficult to manage, that there are rarely ideal solutions to any problem and that room for manoeuvre is limited by multiple constraints. Policy-making itself becomes an experimental and incremental process which takes place against a background of the often conflicting dictates of efficiency, equity and patient empowerment.

Griffiths et al. (2000) reject the view that research organizations are concrete entities that can be systematically described and explained, but see a fragile world that is socially constructed - "nonhierarchical organizations with informal internal relationships based on trust and co-operation and driven by a common ethic'. A world that can accommodate goalseeking behaviour, but is cognizant of the importance of network, history, relationships, cultures and aspirations. Davies and Nutley (2000) have drawn upon complexity theory to describe the evolution of "learning organizations' within the NHS, stressing the importance of rich interactions from which organizations emerge. Royston and Dick (1998) have drawn upon the analogy of an ecosystem to understand health care systems and capture the essentials of their complexities.

These insights may offer a new direction for the third phase of primary care research methodology to complement the more traditional approaches. Primary Care Trusts offer the obvious focus for these developments embedding research into the practical realities of resource decisions. However, this move would not be without its problems.
Pragmatic considerations may stifle research innovation and managers may be reluctant to nurture a research culture within a performance-managed framework. There is also danger of over optimistic expectations - research techniques cannot be applied to every resource allocation question and in most cases there will be no easy answers. The development of this new culture will evolve slowly and inevitably, results will lag behind the requirements of policy-makers.

There can be no universal model for this third phase, each trust will have to recognize and develop its own local strengths. In some cases research active Primary Care Trusts may emerge from a leading research practice or individual, others from existing networks or links with university departments. Ultimately, primary care research funds could be channelled through researchcapable trusts with regional Research and Development Executives offering technical assistance and research governance. A useful first step would be for the Government to acknowledge this new approach so that existing researchers can begin to realign their priorities.

\section{Conflict of interest}

David Kernick and Jonathan Stead are lead research GPs in practices that receive funding from the NHS R\&D Executive. Jonathan Stead is a consultant in clinical effectiveness for the North \& East Devon Health Authority. Professor Yvonne Carter was former Chairman of the Research Committee of the Royal College of General Practitioners.

\section{References}

Blaxter, M. 1995: Consumers and research in the NHS. London: DOH.

Davies, H. and Nutley, S. 2000: Developing learning organisations in the new NHS. British Medical Journal 320, 998-1001.

Department of Health 2000a: The NHS plan. A plan for investment. A plan for reform. London: HMSO.

Department of Health 2000b: Research and development for a first class service. Research and development fundingin the new NHS. London: HMSO.

Department of Health 1996: Primary care: delivering the future. London: HMSO.

Department of Health 1997: Research and development in primary care (National Working Group Report). London: HMSO. 
Griffiths, F., Wild, A., Harvey, J. and Fenton, E. 2000: The productivity of primary care research networks. British Journal of General Practice 50, 913-15.

House of Lords Committee on Science and Technology 1988: Priorities and medical research. London: HMSO.

Marshall, M. 1999: Improving quality in general practice: qualitative case study of barriers faced by health authorities. British Medical Journal 319, 164-167.

Peckham, M. 1999: Developing the National Health Service: A model for public services. Lancet 354, 1539-1545.

Royston, G. and Dick, P. 1998: Healthcare ecology. British Journal of Health Care Management 4, 238-41.
Salisbury, C., Bosenquet, N., Williamson, E. et al. 1998: The implementation of evidence-based medicine in general practice prescribing. British Journal of General Practice 48, 849-51.

Swailes, J.D. 2000: Science and healthcare: An uneasy partnership. Lancet 355, 1637-40.

Tallon, D., Chard, J. and Dieppe, P. 2000: Relation between the agendas of the research community and the research consumer. Lancet 355, 2037-40.

Whitford, D., Jelly, D., Gandy, S., Southern, A. et al. 2000: Making research relevant to the primary care team. British Journal of General Practice 50, 573-6.

\section{Networking page submissions}

If you are part of a Primary Health Care Research Network, or if you would like to comment on such networks, you are encouraged to submit a commentary of up to 300-400 words to Dr Karin Friedli at the address below. Longer pieces on other networking topics may also be considered in consultation with the co-ordinator.

Dr Karin Friedli

HertNet Co-ordinator

Faculty of Health and Human Sciences

University of Hertfordshire

College Lane

Hatfield

Herts AL10 9AB

E mail: k.friedli@herts.ac.uk

Tel: 01707284000

Subject to Editorial review 